\title{
PERFORATING ULCER OF THE FOOT IN ALCOHOLIC NEURITIS
}

\author{
REPORT OF A CASE
}

\author{
ROY M. VAN WART, M.D., C.M. \\ NEW ORLEANS
}

The occurrence of perforating ulcer of the foot with certain disorders of the nervous system has long been recognized. The first description was given by Nélaton in 1852. Since that time the condition has been described in connection with a number of nervous conditions. It is frequent in diseases of the spinal cord, such as tabes and syringomyelia, and has been noted in spina bifida, diseases of the conus medullaris, diabetes and alcoholism. Injuries to the sciatic and tibial, as well as tumors and Iocal inflammatory disturbances of these nerves, have also caused this condition. It is frequent in the neuritis of leprosy. Its occurrence in multiple neuritis, aside from the form due to diabetes, is very infrequent. In the accessible literature I have not been able to find any record of its occurrence in alcoholic neuritis. Sonnenburg noted it in an alcoholic with anesthesia of the foot. Remak and Flatan, ${ }^{1}$ writing in 1899, say: "So scheinen Fülle von Alcoholneuritis mit Mal perfor'unt nicht mitgetheilt zu sein, wenn auch die Möglichkeit dicses Vorkommen durchaus nicht bestritten werden soll."

History.-The patient was a white male, aged $3 \pi$, with a negative family his. tory. He denied syphilis. His work entailed a great deal of loss of sleep with irregular meals. Owing to a condition of his nervous systen which had best be called a "constitutional neurasthenia," he was easily exhausted, and had tried all sorts of artificial means to keep up his strength. For some months prior to the onset of his trouble he had been using alcohol in the form of whisky in large quantities. For three months before the onset of his illness he had been taking not less than a quart a day. He continued to work and took very little food. He came under my observation in October, 1898. His illness had commenced gradually three months before this, with pains in the legs, followed by weakness and atrophy of the muscles, hyperesthesia and redness of the skin. About a month after the onset of the trouble in his legs the hands and arms also became involved. He had been under treatment for two months. At the time I first saw him he complained of great pain in the legs, particularly at night, hyperesthesia of the skin below the knee, and marked tenderness in the muscle groups of the legs and arms. He was unable to walk and could with great difficulty use his aj'ms to feed himself.

1. Nothnagel: Specielle Pathologie und Therapie, Viemma, 1899, xi, Th. III: Abth. JII. 
First Physical Examination.-This showed a poorly nourished man with gray hair. The mucous membranes were pale. He was lying in bed in the dorsal decubitus. The examination of the thoracic and abdominal organs showed nothing of note. The patient had no lymphatic enlargement, and no bladder or rectal disturbances. The nervous system showed no involvement of the cranial nerves. The pupils were equal and reacted to light directly and consensually and to accommodation. The upper extremity reflexes were elicited with difficulty. The abdominal and cremaster reflexes were very sluggish. The knee-jerks, Achilles tendon reflexes and plantar reflexes were absent. There was marked weakness of the extensor and flexor groups of the wrist and fingers. This was most evident in the extensor groups, giving rise to the typical "wrist-drop." There was great muscular atrophy and motor weakness of both lower extremities, the power of the flexors and extensors of the toes and feet being practically wanting. The quadriceps groups and flexor group of the back of the thigh showed a diminished motor power.

Sensation: There was marked hyperesthesia of the skin of the feet and legs. The pain and temperature sensation were practically wanting from below the knees and below the wrists in the upper extremities. The touch sensation of the upper extremities was also much diminished. Touch sensation in the lower extremities was much delayed and, except in the hyperesthetic areas, was almost wanting. The muscles of the calves and of the thigh were very tender on pressure. The nerves were tender, but no swelling could be made out on palpation.

Course of Disease.-The patient's recovery was uninterrupted and he returned to his home in the spring. At this time he was able to walk with the assistance of two canes. In July of the present year, after considerable walking, he noticed that the skin over the distal ends of the third metatarsal bones of both feet was greatly thickened. Later the center of this area broke down, leaving a large ulcerated area; this extended in quite deeply and discharged a considerable quan. tity of pus. These ulcerated areas differed in no way from the perforating ulcers seen in tabes dorsalis. At first they were not very painful, but as the sensation improved the patient noticed that the pain increased. If he would keep perfectly still the pain would not be very marked. The ulcer on the left foot was much larger and deeper than the one on the right foot. At its maximum, it extended three-quarters of an inch across, and in the deep fascia. As far as could be ascertained, there had been no involvement of the tendons or of the deeper structures. The skin surrounding these areas was anesthetic to pain; but, as the sensation continued to improve, the ulcers became very painful. The causation of these ulcers was of some interest. The patient had a flattening of the anterior arch of both feet, and the thickening had existed for some time prior to the onset of his neuritis. This thickening had occurred over the head of the third metatarsal bones, and is very commonly seen in cases of flattening of the anterior arch. The pressure caused by continued walking, with the lowered trophic condition due to the inflammation of the peripheral nerves, was probably responsible for the ulceration. As the neuritis improved the ulcers slowly healed.

Second Physical Examination.-In November, 1908, the knee-jerks, Achilles tendon reflexes, and plantar reflexes had returned. The sensation showed an absence of capability to distinguish the light touch of cotton and the light prick of a pin in the feet. The deep sensation, formerly absent, was now normal. The sensation of the legs was normal. The fact that sensation had not completely returned is in keeping with the studies of Head, as he has shown that as long as two years may elapse without the return of the finer or epicritic sensation; and, in this instance, the sensory loss belongs to this type. 
'The case is of interest as showing how the flattening of the anterior arch, a condition which, under normal circumstances, only gave rise to great thickening of the skin, had, when the neuritis was added, produced typical perforating ulcers. As a rule, trophic ulcers occur at the points of pressure at the base of the great and little toes. This central point seems to be the next in frequency. It would be of interest to note whether this flattening of the anterior arch might not be an important factor in the localization of perforating ulcers in tabes and other conditions. Since the preceding portion of this was written, in fact, a case of tabes dorsalis has been observed in which perforating ulcers, involving the deep structures in this situation, were associated with flattening of the anterior arches.

124 Baronne Street. 